\title{
Assessment of Nutrients and Load of Organic Carbon in Soil and Sediments Due To Flood and Heavy Irrigation of River Krishna in the Bagalkot District
}

\author{
Dr. B. M. Kalshetty ${ }^{1 *}$, R. C. Sheth ${ }^{1}$, Shobha N. ${ }^{2}$ and Mallikarjun B. Kalshetty ${ }^{2}$ \\ Department of Chemistry, BLDEA'S Science College Jamkhandi, Dist: Bagalkot, (K.S). \\ Research and Development Centre, Bharathiar University, Coimbatore (TN), India. \\ P.G. Department of Studies in Chemistry, Karnatak University Dharwad (Karnataka),
}

\begin{abstract}
Levels of chemical parameters ( $p H, E C, N a \& C a$ ), Major nutrients (Organic Carbon, Available Nitrogen, Phosphorous and Potassium) and Micro nutrients ( Fe, $\mathrm{Mn}, \mathrm{Zn}, \mathrm{Cu}$, Boron and Molybdenum) were determined in soil and sediments samples of cultivated lands around the belt of River Krishna across the Bagalkot district, Karnataka state, India. The present study aim was to evaluate some physical and chemical properties, assessment of Organic load, nutrients and their special variation in soil and sediment samples due to heavy irrigation of cultivated lands. The spatial variability and distribution of soil properties at the cultivated lands affect yield potential, hydrologic responses and transport of herbicides to soil surface. The study reveals the seasonal effect on soil and sediment properties by flood and heavy irrigation, fertilizer addition, high water table level and agriculture practices. This effect may cause positive and negative Organic load and nutrients on soil properties. For this evaluation 12 soil samples (seasonally 4 samples each) from soil surface for layer according to grid sampling design and12 sediment samples at three different seasons with 1000 to 2000 meters distance based soil and sediments variability were selected and analyzed.
\end{abstract}

Key Words: Organic Carbon, Nutrients, Soil and Sediment samples, spatial variability in soil properties.

\section{Introduction}

Bagalkot located at the northern part of Karnataka State and is noted as one of the largest granite mining and polishing centers. Also found the largest amount of Sulphide ores deposited in the form of Manganese and Iron in this region. The maximum number of Dolomite ore smelting processes is located throughout the district around the Krishna River belt. Since last decades the mining and smelting activities increased, the sulphurdioxide and trace metal emission from mining and smelters have contaminated local lake, ground water, municipal water and River Krishna water body. It was reported the Fluoride concentration found maximum in the area of Bagalkot specially Hunagund, Ilakal and Badami taluks, so it is proper time to study on effect of Fluorosis diseases and threat to human health $[1,2]$.

The polluting Contaminants in water, soil and sediments samples pose a threat to human health, aquatic life and environment [3]. Pollutants release to surface water from industrial and municipal discharges, polluted runoff from agricultural activity, urban and mining area can accumulate to environmentally harmful levels in soil and sediment samples[4]. The industrial effluents of sugar industries available on the shore of River Krishna in the study are were discharging at the different dumpsites; discharged effluents were killing he water quality and reduce the dissolved Oxygen level to very critical. The toxicity tests in the laboratory with ambient water and with soil-sediments from the suspected polluted area can be used to confirm toxic agents in the region.

\section{Samplings:}

\section{Materials And Methods}

Surface sediment samples were collected by scrapping using a pre-cleaned and acid washed plastic scale and immediately kept in clean polythene bags, the dried sediment samples $(50 \mathrm{mg})$ were digested in $2 \mathrm{ml}$ Nitric acid $(70 \%)$ Merck, in a block thermostat at $80^{\circ} \mathrm{C}$ for 3 to 4 hours until the solutions were clear [5]. The extracted sediment solutions then made up to $25 \mathrm{ml}$ with double distilled water in $25 \mathrm{ml}$ volumetric flasks the micro nutrients (trace metals) were analyzed in all samples by using Atomic Absorption Spectrophotometer (AAS Elico). The sediments were analyzed for physico - chemical parameters using respective instruments, Major and Secondary nutrients were analyzed according to the standard procedures by using Nitrogen analyzer and Flame photometer respectively, the values obtained were within $10 \%$ range for the reference values.

Surface water samples of River Krishna were collected with 500 to 1000 meters distances in cleaned polythene bottles seasonally fitted with Teflon caps. Shortly after collection, samples were filtered through Whatmann filter papers ( 0.4 micrometer pore diameter) and aliquots of filters were stored in cleaned polyethylene bottles. The samples were analyzed for Fe, Mn, Zn, Cu by using AAS -Elico. The accuracy of 
dissolved heavy metal determinations were indicated by good agreement between our observed values[6,7] and so far reported standards of WHO and BIS.

Soil samples were collected in different seasons in polyethylene bags as per the standard methods (Grid sampling design). 5 grams of soil samples were taken in to $150 \mathrm{ml}$ conical flask separately, $50 \mathrm{ml}$ of $0.1 \mathrm{M} \mathrm{HCl}$ was added and the flasks were kept on shaker for 30 minutes. The contents were filtered into $50 \mathrm{ml}$ standard flask and made up to the mark with $0.1 \mathrm{M} \mathrm{HCl}$ for determination of micro nutrients using AAS - Elico.

The physico - chemical parameters, Major and secondary nutrients in the soil samples were determined by preparing soil extraction with suitable solvents, using $\mathrm{pH}$ meter, Flame photometers, Visible spectrophotometer and Nitrogen analyzer (All are of Elico model). All the reagents used were of Analytical grade, demonized water (18 mega ohm resistivity) prepared from Millipore milli-Q water purification system (USA), was used throughout. Hydrochloric acid (40\% pure), Nitric acid used were of pure (Merck).

\section{Results And Discussion:}

The analytical data of Physico-Chemical parameters of River Krishna water (surface water) for three seasons were recorded in Table 1. Similarly Table 2 and Table 3 indicate the soil and sediment samples analysis results in three different monitoring periods (Pre-Monsoon, Monsoon and Post- Monsoon) All the values were compared with WHO, ISI and Bureau of standards. The deficiency of Micro-Nutrients (Boron, Zinc and Sulphur) \& Major nutrient such as Organic Carbon in the soil samples of Bagalkot District after the flood effect were shown in the charts. The Figure I and Figure II reveals the comparative study of micro- Nutrients in the soil samples found after flood and heavy irrigation.

\section{Surface water $\mathbf{p H}$ and Other chemical parameters:}

The surface water $\mathrm{pH}$ exhibited variation within a small range in all three seasons (Pre-monsoon, Monsoon and Post-monsoon), highest values were recorded during Pre-monsoon (pH: 7.28) this is because the lean flow of water during summer days, and lowest value (pH: 7.11) was recorded during monsoon (rainy) this might be due to natural purification and flooded flow of water. The $\mathrm{pH}$ value found to be 7.18 at post-monsoon (winter) season. The variation of $\mathrm{pH}$-values and become lower value at monsoon clearly confirms the phenomenon of acidification of river Krishna water in the study area. The same trend was noticed in the ECvalues in the three different seasons. The order of chemical parameters such as TDS, DO, TH, Calcium, Magnesium, etc., will be found as : Pre-monsoon > Monsoon < Post-monsoon.

\section{Dissolved metals in water samples:}

The relative order of dissolved heavy metals like $\mathrm{Fe}, \mathrm{Mn}, \mathrm{Cu}, \mathrm{Zn}$ in the River Krishna surface water is found as: $\mathrm{Fe}>\mathrm{Zn}>\mathrm{Mn}>\mathrm{Cu}$ in ppb values at all three seasons. Dissolved $\mathrm{Zn}$ ranged from 34.01ppb during monsoon to $40.30 \mathrm{ppb}$ during pre-monsoon. Dissolved $\mathrm{Cu}$ ranged from $0.301 \mathrm{ppb}$ to $0.378 \mathrm{ppb}$ from monsoon to pre-monsoon, where as its value during post-monsoon were found to be $0.352 \mathrm{ppb}$. The Manganese found in the range of $11.01 \mathrm{ppb}, 18.14 \mathrm{ppb}$ and $28.01 \mathrm{ppb}$ during Monsoon, post monsoon and pre-monsoon respectively. Fe found in higher concentration ranged in between $450 \mathrm{ppb}$ to $472 \mathrm{ppb}$ during the three monitoring periods.

\section{3. pH of soil and sediment samples: How? Soil pH is increased:}

Soil quality is one of the serous environmental problems. Soil contaminations influence the geochemical reactions and may change environmental behavior. Fertility of soil and sediments dependent upon the amount of organic matter, types of clay (Texture), water holding capacity and also dependent upon nature of soil (acidic or alkaline).

Soil pH and Plant Growth: soil $\mathrm{pH}$ is a measure of the acidity or alkalinity. The optimal $\mathrm{pH}$ of soils should be in between $6.5-7.5$. Acidic soil affects availability of plant nutrients. Acidic soil results in an increase in Aluminum. Aluminum is toxic to plants. The availability of toxic metals in soil affects the activity of soil micro-organisms [8], thus affecting nutrient cyclining and disease risk. Liming materials (pure $\mathrm{CaCO} 3$ or Dolomite lime) will increase soil $\mathrm{pH}$. Lime is a certified Organic product does not add every year. But, 15$20 \mathrm{lbs}$ lime per 1000 sq.ft. is recommended. Wood ashes are another product to raise soil $\mathrm{pH}$ (wood ashes also are a sources of $\mathrm{K}, \mathrm{Ca}$ and $\mathrm{Mg}$ ). Some compost also can increase soil $\mathrm{pH}$. Elemental sulphur is often recommended (50 lbs sulphur per $1000 \mathrm{sq}$. ft.) Ammonium and Ammonium forming $\mathrm{N}$-fertilizers will also result in a decrease in soil $\mathrm{pH}$. In the present investigation the $\mathrm{pH}$ of the soil and sediment samples during the three seasons found in between 8.23 to 8.76 and 8.34 to 8.68 , this is the indication of soils and sediments are found alkaline in nature.

\section{Salinity of soil and sediment samples:}

Salts in soil and sediment samples can come from irrigation and water table in the cultivated lands, using composts and Inorganic fertilizers. The potential problem in irrigated soils due to high evaporation rates and low annual rain fall leaving salts to accumulate. Salts can be leached by slowly applying excess water (3 inches removes about $50 \%$ of the soluble salt and 5 inches removes at $90 \%$ ).

Soil salinity measured and justified by the EC values, if the Conductivity (EC) $\mathrm{m}$ mho / $\mathrm{cm}$ found more than 4 (4 or above) the soil and sediment possesses severe accumulation of salts may restrict growth of many 
vegetations. EC values in between $2-4 \mathrm{~m}$ mho $/ \mathrm{cm}$ showed moderate accumulation of salts will not restrict plant growth, but may require more frequent irrigation. The soil and sediment samples EC values found less than $2 \mathrm{~m}$ mho / $\mathrm{cm}$ indicates low salt accumulation will not affect plants. In the present investigation the EC values recorded in both soil and sediment samples ranged in between $1.274 \mathrm{~m}$ mho $/ \mathrm{cm}$ to $2.298 \mathrm{~m} \mathrm{mho} / \mathrm{cm}$ and $2.290 \mathrm{~m} \mathrm{mho} / \mathrm{cm}$ to $2.370 \mathrm{~m} \mathrm{mho} / \mathrm{cm}$. All values found more than the permissible legal limits. Hence, the soil and sediment samples showed the moderate accumulation of salt will not restrict plant growth.

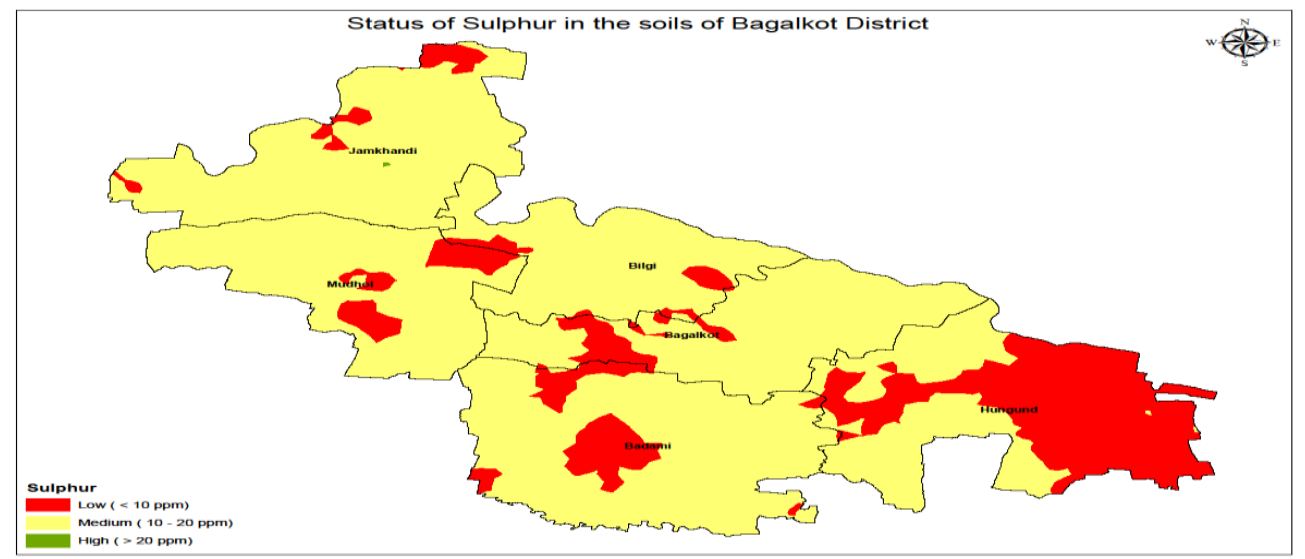

\section{Cation Exchange Capacity (CEC):}

The secondary nutrients such as Calcium (\%), Magnesium (\%) and sulphate (ppm) are also quite essential for the plants vegetations growth. Most nutrients are cations: $\mathrm{Ca}^{+2}, \mathrm{Mg}^{+2}, \mathrm{~K}^{+}, \mathrm{Zn}^{+2}, \mathrm{NH}_{4}^{+}, \mathrm{Cu}^{+2}, \mathrm{Mn}^{+2}$, the cations are in the soil and sediment solution and are in dynamic equilibrium with the cation absorbed on the surface of the clay and Organic matter. The CEC is dependent upon the amount of Organic Matter and types of clay in soils. In the present investigation the Electrical Conductivity recorded for soil samples were found less than that of sediment samples this is because of deposition of said secondary nutrients in the surface sediments due to the flood and water spreading during the period of the irrigation.

\section{Sediment metals:}

The order of biologically available heavy metals in ppm values of surface sediment samples is found as: $\mathrm{Fe}>\mathrm{Cu}>\mathrm{Mn}>\mathrm{Zn}$. In case of $\mathrm{Zn}$ the values ranged from $0.673 \mathrm{ppm}, 0.612 \mathrm{ppm}$ and $0.812 \mathrm{ppm}$ in premonsoon, monsoon and post-monsoon respectively, $\mathrm{Zn}$ ion concentration found less in surface sediment samples because of flood and more rainfalls and natural purification. $\mathrm{Cu}$ also found in the trend in the different seasons the lowest value of $\mathrm{Cu}$ in same sediments were found to be $2.728 \mathrm{ppm}$, maximum value of $\mathrm{Cu} 3.280$ ppm found during post-monsoon season, the texture of cultivated lands were found to be dry with clay loam soil- sediments. In case of Fe the lowest value was observed during pre-monsoon $(3.91 \mathrm{ppm})$ and the highest value was recorded during post-monsoon $(4.12 \mathrm{ppm})$. The same trends were also found for $\mathrm{Mn}$ ion concentration seasonally in surface sediments. Zn metal ions found more than the prescribed limit in soil samples where as in sediment samples found within the prescribed legal limits $(0.750 \mathrm{ppm})$. So soil becomes little bit critical for sensitive crops because of higher concentration of $\mathrm{Zn}$ (micro-nutrient) rather than sediments.

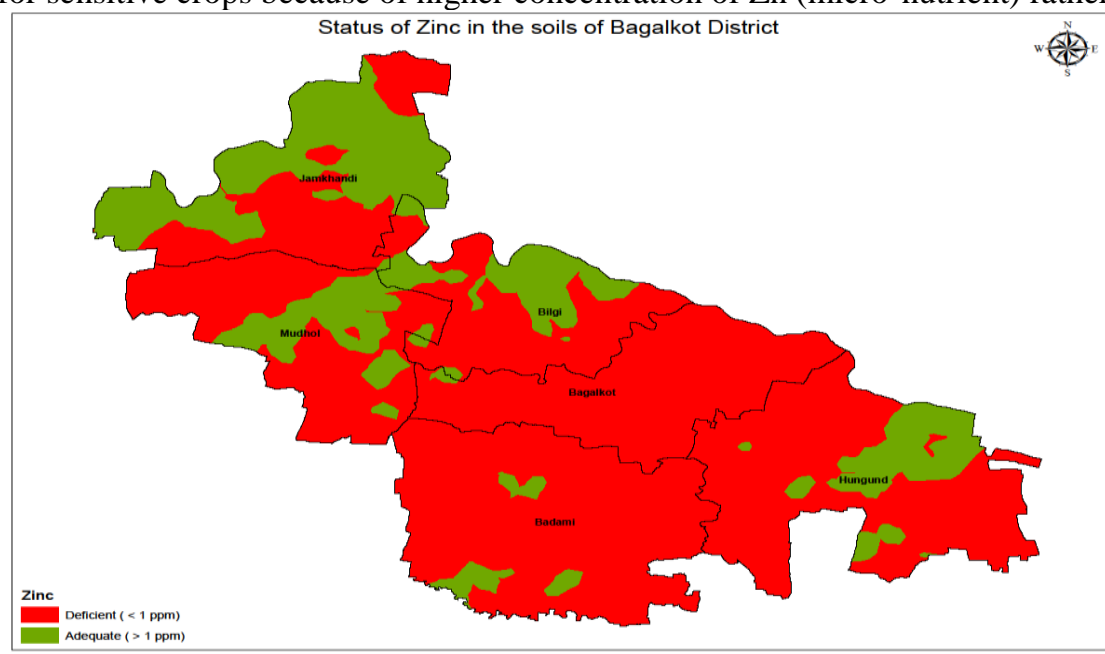




\section{Total Organic Carbon in soil and sediment samples:}

Organic carbon enters the soil sand sediments through the decomposition of plant and animal residues, root exudates, living and dead micro-organisms and soil-biota. Soil organic matter is the organic fraction of soil exclusive of no decomposed plant and animal residues; most analytic methods don't distinguish between decomposed and non-decomposed residues. The soil organic carbon is a heterogeneous, dynamic substance that varies in particle size, carbon content, decomposition rate and turn over time. The soil and sediments were highly fertile if they possess the Organic carbon in nano- particle size. Thus, the soil organic carbon is the main sources of energy for soil micro- organisms.

In the present investigation the soil and surface sediment samples possessed the percentage of $\mathrm{OC}$ within the prescribed legal limit $(0.50-0.75 \mathrm{ppm})$. Hence, the percentage of $\mathrm{OC}$ in soil samples ranged in between $0.65 \%$ to $0.69 \%$ where as in sediment samples OC found in between $0.56 \%$ to $0.59 \%$ during monitoring periods. This reveals that both the soil and sediment samples found to be fertile, this is because of the OC is one of the important constituents of the soil and its capacity to effect plant growth as both a source of energy and a trigger for nutrient availability through mineralization. The OC plays in maintaining the stability of nutrient and water holding capacity. The Organic compounds in soil bind mineral particles together into micro-aggregates and stabilizers soil structure making soil resistant to erosion, but porous enough to allow air, water and plant roots to move through the soil.

On the decomposition of Organic residues and manures, organic acids commonly released may prevents Phosphorous fixation by clay minerals and improve its plant availability in the subtropical and tropical soils. On increase in soil organic matter and total organic carbon leads to greater biological diversity in the soil, this increasing biological control of plant disease. The important function of $\mathrm{OC}$ released by soil organic manures should interact with pesticides and helps in pesticide movement through soil into ground water.

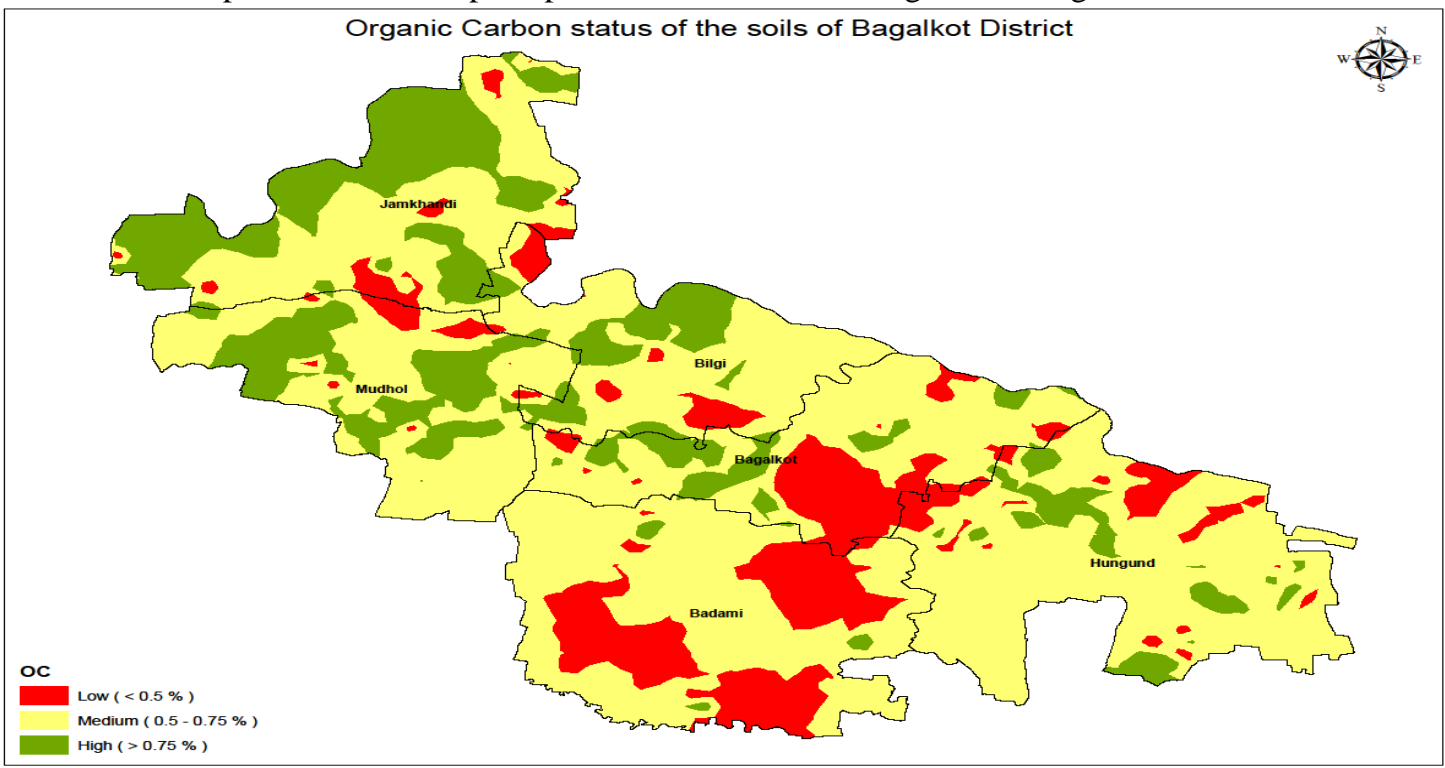

The deficiency of OC in soils reduces the biomass activity and nutrient mineralization processes. The scarce oil OC results in the less diversity in soil biota with a risk of the food chain equilibrium being disrupted, which can cause disturbance in the soil environment. Hence, the plant pest and disease increase accumulation of toxic substance in soils. Organic Carbon supports vegetation growth. OC is related to Organic matter (Manures) and it is correlated to the amount of vegetation cover in the area. OC is one of the major sources of soil fertility particularly for Nitrogen and Phosphorous. 


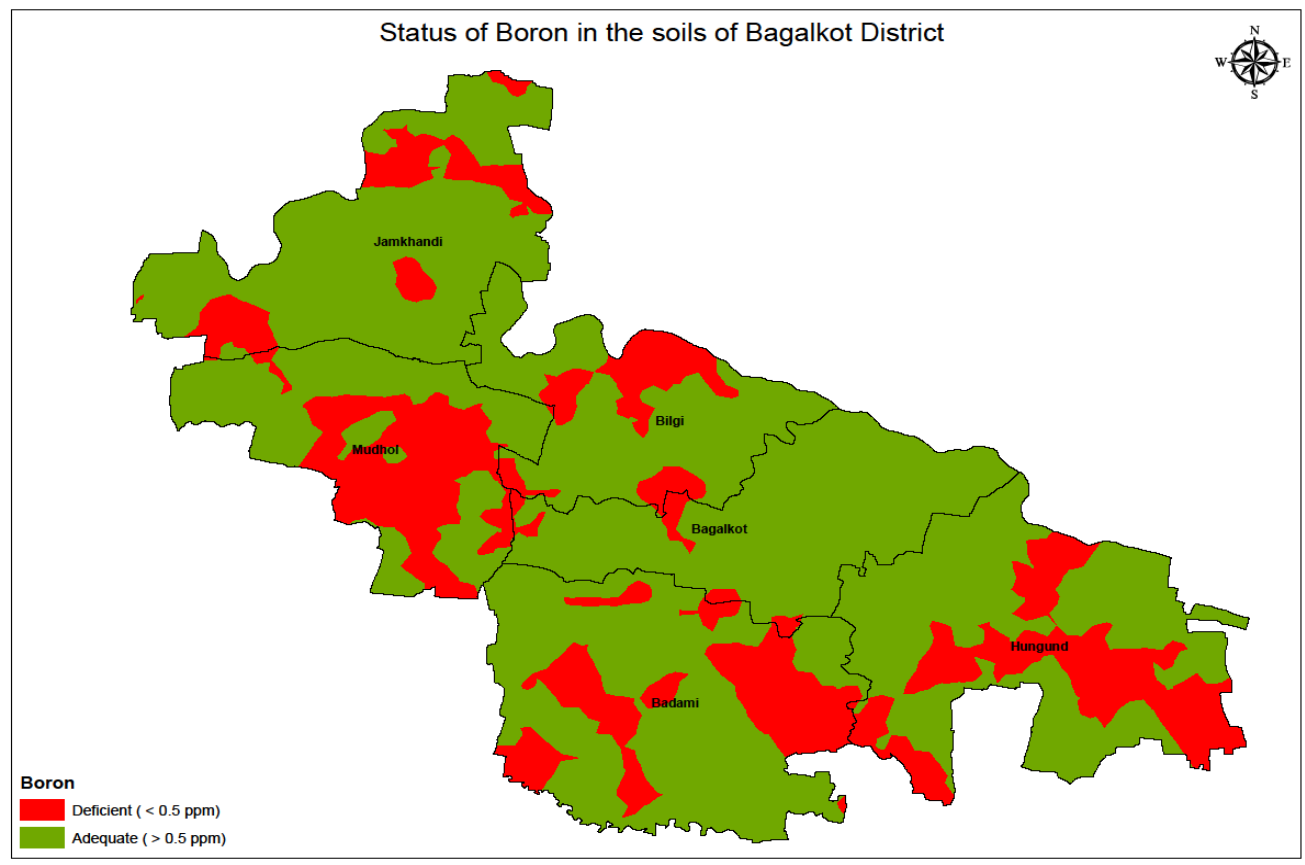

IV. Conclusion:

The objective of our present investigation was to determine the impact of the flood and heavy irrigation on Physico- chemical properties and nutrients status of flooded soils and surface sediments of cultivated areas in order to provide a quick estimate of flood effects on the conditions for agricultural production in flooded and heavy irrigated area. The possible effects were observed to be heavy metal ions (micronutrients) enrichment in the sediment, and the change of the nutrient status of the soils. The concentration of heavy metals in the sediment layer left from the flood was more or less below legal limits except Iron, Zinc and Copper. The nutrient status such as Zinc, Boron and the major nutrient Organic Carbon were shown by nutrient charts of the soils, the reduced in available Phosphorus in soil samples, and the percentage of Magnesium (Mg) found more or less within the permissible limits, and increase in Potassium contents were measured in the soils $(170.2 \mathrm{~kg} / \mathrm{h}$ to $372.9 \mathrm{~kg} / \mathrm{h}$ ) in the soil samples of flooded area. The $\mathrm{pH}$ values recorded in almost all spots of flooded area were more than the legal limits. The relative contribution of protons to the CEC was also reduced. The mineral nitrogen content was appreciably decreased in the area of flooded sediment soils. This effect could most probably be related to denitrification processes as result of anaerobic conditions during the flood and water spreading factor.

The conclusion is drawn that the effects of the flood on the conditions for agricultural production in the cultivated lands of the Bagalkot District (128 $\mathrm{Km}^{2}$ area). The total soil evaluation be recorded as the fertile land with high production potential has been reduced. Major Effects on the flood were the direct crops losses and the destruction of agricultural infrastructure. However, given the major damage to leaving beings and social casts the flood caused in the entire catchment area.

\section{Acknowledgements:}

The authors are thankful to Dr. N. Gopukumar, Deputy Secretary, UGC, and South Western Regional Office Bangalore for their help and encouragement by funding the financial assistance in term of Minor Research Project. Authors express their sincere thanks to Dr. C.N.R.Rao, FRS National Research Professor, Chairman Vision Group on Science and Technology, Bangalore and Dr. Ananth Raj Executive Secretary VGST group, Bangalore for providing financial support in terms of Major Projects. The authors are also thankful to Dr. B.G.Mulinami Vice- Chancellor and chief Administrative Officer \& S.H.Lagali and S.K.Biradar Administrative Officers BLDE'S Association Bijapur and Principal Dr. S.S.Suvarnakhandi for providing necessary facilities required to carry out this research work. We are very much thankful to Principal B.V.V.S. Polytechnic College Bagalkot for providing Instrumental facility required to carry out this research work. 


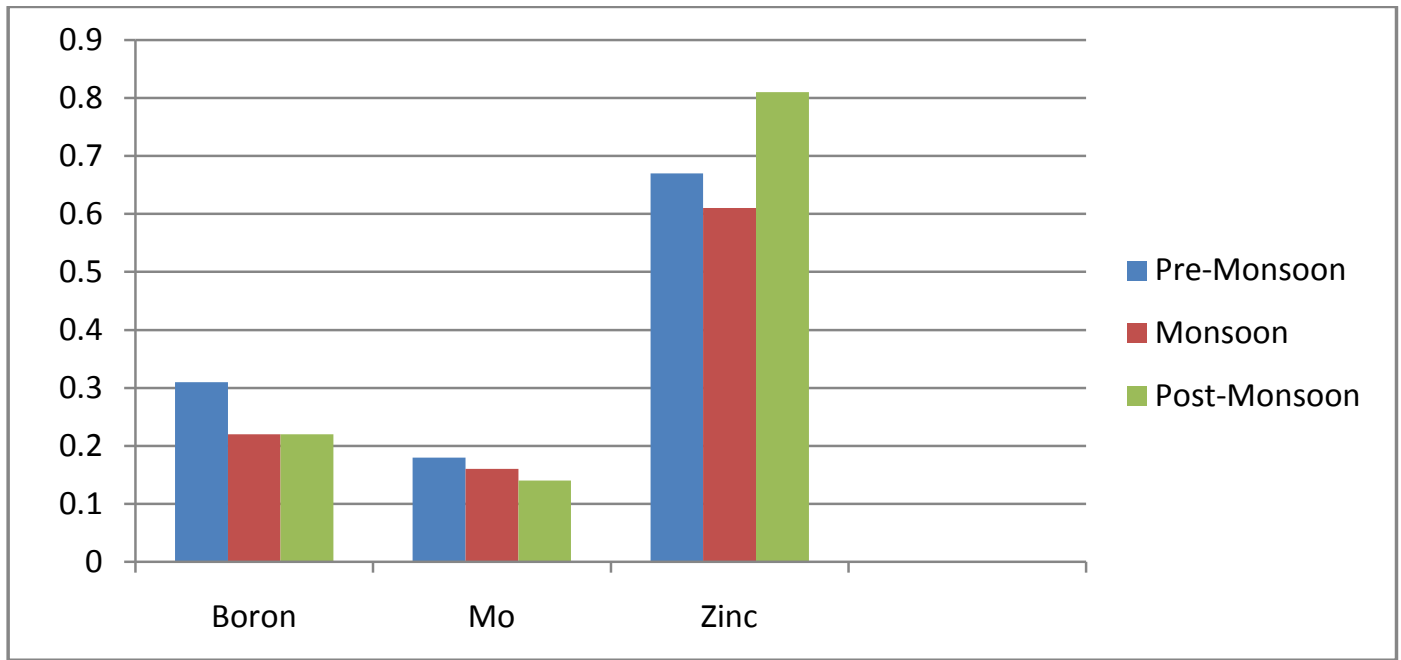

Figure I: Seasonal Variation in Micro-Nutrients (Boron, Molybdenum \& Zinc).

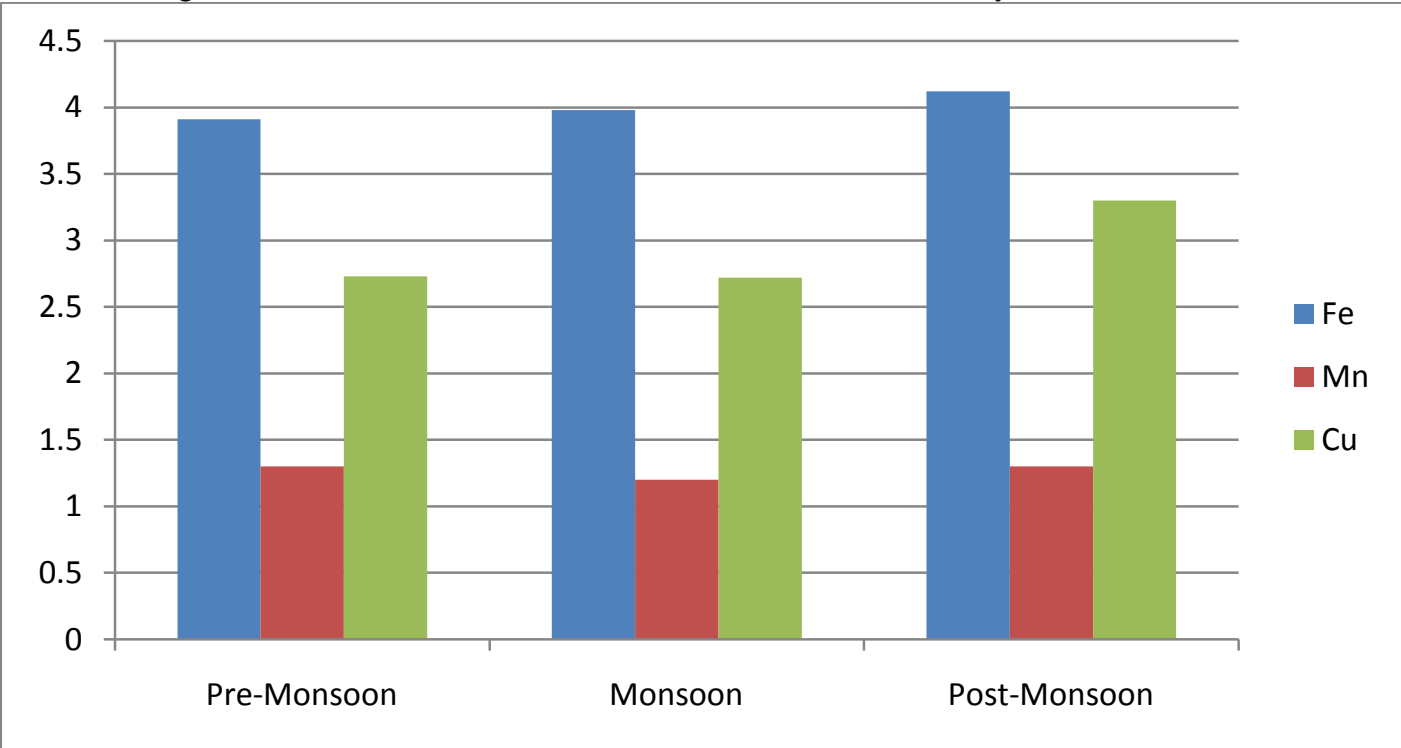

Figure II: Seasonal Variation in Micro-Nutrients (Iron, Manganese \& Copper).

Table 1.

Analytical Results of River Water at different seasons

(Pre-monsoon, Monsoon and Post-monsoon)

\begin{tabular}{|c|c|c|c|c|c|}
\hline Parameters & Unit & Pre-monsoon & Monsoon & Post-monsoon & Legal limits. \\
\hline $\mathrm{pH}$ & --- & 7.28 & 7.11 & 7.18 & $6.5-7.8$ \\
\hline $\mathrm{EC}$ & $\mathrm{ds} / \mathrm{m}$ & 1.50 & 1.20 & 1.30 & $1.4 \mathrm{ds} / \mathrm{m}$ \\
\hline TDS & Ppm & 992 & 710 & 865 & $<500$ \\
\hline TA & "6 & 524.4 & 441.1 & 484.8 & 120 \\
\hline $\mathrm{TH}$ & “" & 367.4 & 222.6 & 284.3 & 300 \\
\hline $\mathrm{Na}$ & " & 1.9 & 1.6 & 1.8 & 200 \\
\hline $\mathrm{K}$ & “ & 0.612 & 0.515 & 0.561 & 1.4 \\
\hline DO & “" & 6.5 & 6.4 & 6.4 & 7.0 \\
\hline CO3' & “" & 34 & 21 & 28 & --- \\
\hline HCO3' & “" & 154 & 142 & 148 & --- \\
\hline $\mathrm{Cl}$ & " & 128 & 110 & 118 & 250 \\
\hline NO3 & " & 60 & 49 & 52 & 40 \\
\hline $\mathrm{SO} 4$ & “" & 74 & 61 & 70 & $75-100$ \\
\hline Calcium & “" & 42 & 30 & 35 & $75-100$ \\
\hline $\mathrm{Mg}$ & $" 6$ & 64 & 36 & 48 & $30-150$ \\
\hline $\mathrm{Fe}$ & $\mathrm{Ppb}$ & 472 & 450 & 460 & $<1$ \\
\hline $\mathrm{Mn}$ & $\mathrm{Ppb}$ & 28.01 & 11.01 & 18.14 & 2.0 \\
\hline Copper & $\mathrm{Ppb}$ & 0.378 & 0.301 & 0.352 & 0.60 \\
\hline Zinc & $\mathrm{Ppb}$ & 40.30 & 34.01 & 37.15 & 0.75 \\
\hline
\end{tabular}


TABLE 2

SOIL AND SEDIMENT ANALYSIS REPORT

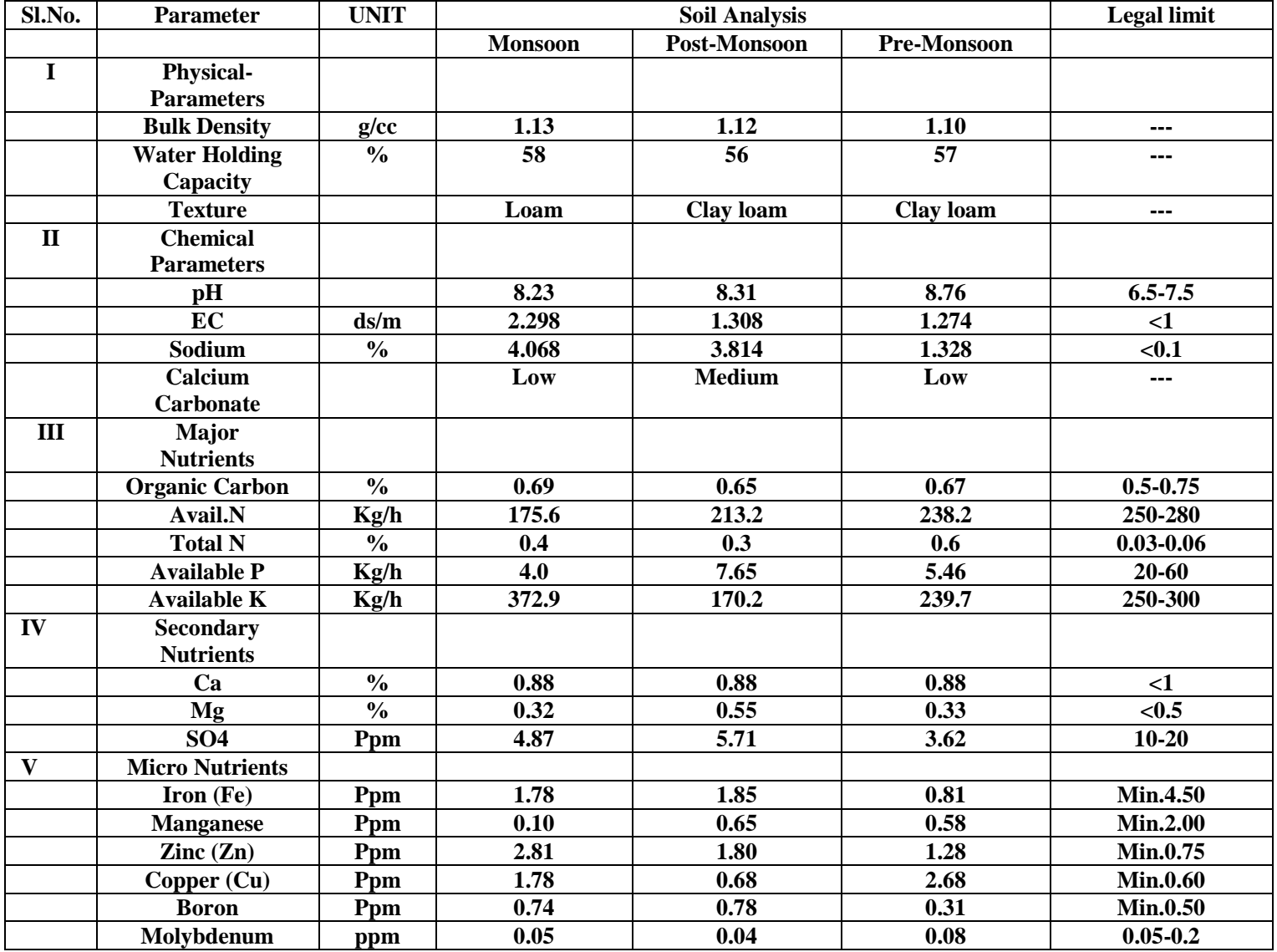

TABLE 3

SOIL AND SEDIMENT ANALYSIS REPORT

\begin{tabular}{|c|c|c|c|c|c|c|}
\hline Sl.No. & Parameter & UNIT & \multicolumn{3}{|c|}{ Sediments Analysis } & \multirow[t]{2}{*}{ Legal limi } \\
\hline & & & Monsoon & $\begin{array}{c}\text { Post- } \\
\text { Monsoon }\end{array}$ & Pre-Monsoon & \\
\hline \multirow[t]{4}{*}{ I } & $\begin{array}{c}\text { Physical- } \\
\text { Parameters }\end{array}$ & & & & & \\
\hline & Bulk Density & g/cc & 1.08 & 1.09 & $\mathbf{1 . 1 0}$ & --- \\
\hline & $\begin{array}{c}\text { Water Holding } \\
\text { Capacity }\end{array}$ & $\%$ & 54 & 52 & 56 & --- \\
\hline & Texture & & Black clay & Black & Black & --- \\
\hline \multirow[t]{5}{*}{ II } & $\begin{array}{c}\text { Chemical } \\
\text { Parameters }\end{array}$ & & & & & \\
\hline & pH & & 8.68 & 8.57 & 8.34 & $6.5-7.5$ \\
\hline & EC & $\mathrm{ds} / \mathrm{m}$ & 2.320 & 2.290 & 2.370 & $<1$ \\
\hline & Sodium & $\%$ & $\mathbf{0 . 7 3 2}$ & 0.726 & 0.728 & $<0.1$ \\
\hline & $\begin{array}{c}\text { Calcium } \\
\text { Carbonate }\end{array}$ & & Medium & Medium & Medium & --- \\
\hline \multirow[t]{6}{*}{ III } & $\begin{array}{c}\text { Major } \\
\text { Nutrients }\end{array}$ & & & & & \\
\hline & Organic Carbon & $\%$ & 0.59 & 0.56 & $\mathbf{0 . 5 8}$ & $0.5-0.75$ \\
\hline & Avail.N & $\mathrm{Kg} / \mathrm{h}$ & 175 & 182 & 188 & $250-280$ \\
\hline & Total N & $\%$ & 0.046 & 0.042 & 0.042 & 0.03-0.06 \\
\hline & Available P & Kg/h & 67.90 & 63.40 & 67.28 & $20-60$ \\
\hline & Available K & Kg/h & 498.7 & 418.5 & 453.1 & $250-300$ \\
\hline \multirow[t]{4}{*}{ IV } & $\begin{array}{c}\text { Secondary } \\
\text { Nutrients } \\
\end{array}$ & & & & & \\
\hline & $\mathbf{C a}$ & $\%$ & 1.72 & 1.88 & 1.88 & $<1$ \\
\hline & Mg & $\%$ & 0.298 & 0.292 & 0.292 & $<0.5$ \\
\hline & SO4 & Ppm & 33.62 & 34.72 & 34.21 & $10-20$ \\
\hline \multirow[t]{3}{*}{$\mathbf{V}$} & Micro Nutrients & & & & & \\
\hline & Iron (Fe) & Ppm & 3.91 & 3.98 & 4.12 & Min.4.50 \\
\hline & Manganese & Ppm & 1.273 & 1.124 & 1.273 & Min.2.00 \\
\hline
\end{tabular}




\begin{tabular}{|l|c|c|c|c|c|c|}
\hline & Zinc (Zn) & Ppm & $\mathbf{0 . 6 7 3}$ & $\mathbf{0 . 6 1 2}$ & $\mathbf{0 . 8 1 2}$ & Min.0.75 \\
\hline & Copper $($ Cu) & Ppm & $\mathbf{2 . 7 3 1}$ & $\mathbf{2 . 7 2 8}$ & $\mathbf{3 . 2 8 0}$ & Min.0.60 \\
\hline & Boron & Ppm & $\mathbf{0 . 1 2}$ & $\mathbf{0 . 1 2}$ & $\mathbf{0 . 1 8}$ & Min.0.50 \\
\hline & Molybdenum & ppm & $\mathbf{0 . 0 4}$ & $\mathbf{0 . 1 8}$ & $\mathbf{0 . 0 8}$ & $\mathbf{0 . 0 5 - 0 . 2}$ \\
\hline
\end{tabular}

\section{References:}

[1]. Hamed Foroghifar, Ali Asghar Jafarzadeh, Hosien Torabi, Naser Aliasgharzad, and Norair Toomanian, "Satial Variability Some Physical and Chemical Proprties Soil surface in Dasht-e-Tabriz Different Landforms" Geophysical Research Abstract Vol. 12, EGU 2011-336-1, 2010

[2]. Anuradha Bhatia, Proceeding of the International Conference on water and Environment (WE-2013), Bhopal, India, 2003;pp 299309.

[3]. Adeyeye, E I. Bull. Chem. Soc. Ethiop. 2005,19,1.

[4]. Shuhaimi - Othman M. "Metal concentration in the sediments and sediment toxicity", Journal of Environmental Science and Technology 1(1): 34-41,2008.

[5]. Malo, BA. "Partial extraction of metals from aquatic sediments, Environmental Science and Technology; 1977, pp. 277-288.

[6]. $\quad$ WHO (World Health Organization). "Guidelines for dringking water quality" $2^{\text {nd }}$ Ed., vol.2. Health critieria and other supporting information, WHO, Geneva, 1997,pp. 940-949.

[7]. APHA, AWWA, WPCE. 15 th Ed., (1980): Standards Methods for the Examination of water and waste water $15^{\text {th }}$ Edition, American Public Health Association Inc., Washington D.C. U.S.A.

[8]. Dr. Kalshetty B M, Dr. Giraddi T P, Sheth R C \& Kalashetti M B, "River Krishna Flood Effects on Soil Properties of Cultivated Areas in Bagalkot District, Karnataka State”. Global Journals Inc. (USA), Volume 12 Issue 6 Version 1.0 Year 2012.

\section{REFERENCE BOOKS:}

[1]. Brady Weil: "The nature and soils properties". 14 $4^{\text {th }}$ Edition

[2]. Shubhrata R. Mishra "Hand Book of soil Science" Discovery Publications New Delhi, First Edition; 201.

[3]. Environmental conservation and sustainable Development, Chawla P. S., Pearl books, New Delhi, First Edition., 2011.

[4]. Fundamentals of soil and water conservation Engineering, Sawant B.P, Awari H.W, Kamble A.M, Tekale D.D, Current Publications, Agra- I edition., 2010.

[5]. Text Book of Environmental Science and Technology, Rajaram Choyal, RBSA Publications, Jaipur, 2012.

[6]. Environmental and Agriculture pollution, Phul Kumar Gaur, RBSA Publications, Jaipur, 2011.

[7]. Vogal A.I. A Text Book of Quantitative Inorganic Analysis, Green: London; 1961. 